\title{
Cartographic Education at the University of Glasgow: Past, present and future
}

\author{
David Forrest \\ School of Geographical \& Earth Sciences, University of Glasgow, UK. david.forrest@ glasgow.ac.uk
}

Keywords: education, University of Glasgow

\begin{abstract}
:
The author is approaching 30 years of delivering cartographic and geospatial science education at the University of Glasgow, mostly associated with specialist undergraduate degrees in Geomatics and MSc programmes in Cartography. This paper reflects on how the curriculum and teaching have changed, particularly in postgraduate programmes. The last year has seen significant challenges and the presentation considers how the sudden forced change in teaching delivery is likely to impact on future delivery of courses. This coincides with a time of some significant staffing developments, including the new position of Professor of Geospatial Data Science, an additional lecturer post, and increased technical and teaching support being available to support geospatial science teaching and research. The presentation will briefly review developments over the last 30 years, with the main focus on recent trends in teaching and learning and how the programme is likely to develop in the coming years.
\end{abstract}

Curriculum development and delivery of a high quality student experience have been at the heart of the author's career. As well as being Programme Director for postgraduate programmes in Cartography for much of the last 30 years, he has also been responsible for major reviews of undergraduate degrees in Geomatics and has been the Convenor of PG Teaching in the School of Geographical \& Earth Sciences for the last 10 years. Within the University, the author was the first Teaching Quality Assurance Officer for the Faculty of Science, has chaired the Science Taught Programmes Committee and Board of Studies, and is currently a member of the University Learning \& Teaching Committee.

In 1990, the University of Glasgow offered a 4-year BSc degree in Topographic Science which had seen modest numbers graduate each year for over 20 years. Overlapping with the delivery of the undergraduate degree, a suite of Postgraduate Diplomas were offered, as was a 2-year Master of Applied Science in Topographic Science. The PG Diploma programmes were Cartography; Digital Mapping and Automated Cartography; Photogrammetry; and Surveying. The MAppSci consisted of the coursework from two of the Diplomas, plus a master's dissertation. The Diploma in Cartography had been offered since 1963 and was deemed a success in those days, achieving 10-12 students most years. It was followed by the Diploma in Photogrammetry, which only ever saw small numbers, and by a Diploma in Surveying in the late 1970s, which rose to have 25-30 students per year by the mid-1980s. In 1979, at a time when postgraduate programmes in GIS were starting to appear, Glasgow introduced the PG Diploma in Digital Mapping and Automated Cartography. While this could have been called GIS, the title made it clear that the Glasgow focus was on using digital systems for map design \& production, rather than spatial analysis, a focus which has continued to this day.

When the author took up a position at the University in 1991, the undergraduate teaching very much followed the philosophy driven by Petrie \& Keates when the programme was developed in the 1960's (Petrie \& Keates, 1968). This, probably more that most programmes in the mapping sciences, significantly integrated the sub-disciplines, giving moreor-less equal weight to cartography, photogrammetry and surveying. Also had for that time, it had an unusual emphasis on group work, problem based learning and student engagement with organising aspects such as field work. At postgraduate level, due to the limited time period - most students opted for the 9-month Diploma, with only a few continuing to the MAppSci - the interdisciplinary approach was less feasible and so each focused on one of the subdisciplines of the mapping sciences. There was a few shared courses, but apart from fairly significant overlap of the Cartography and Digital Mapping \& Automated Cartography programmes, the Diplomas were mostly self-contained.

By the mid-1990s changes in the discipline, in staffing and outside pressures lead to a major review of both undergraduate and postgraduate delivery. The focus of the undergraduate programme shifted from a largely map production line approach to one much more focused on the database as central to the discipline, with other aspects of mapping sciences feeding into or from this (Drummond, et al, 1997). At the postgraduate level, the 2 year MAppSci and the four PG Diplomas were replaced by a single one-year MSc programme in Topographic Science. This had 2 distinct routes: Surveying; and Cartography and Geoinformation Technology. The move to the 1-year MSc very much reflected practice in other UK universities and the need to compete for students. Diplomas covering the taught part of the MSc continued to be available, but most students now opted for the full MSc. Interestingly, much of the mapping industry continued to view those with the Diploma as being adequately qualified and saw MSc project as not essential for employment. The exception is perhaps in GIS, where many job descriptions explicitly require an MSc.

The one year MSc in Topographic Science programme had four elements. 1) A core covering fundamental aspects of geospatial sciences taken by all students, which made up over $30 \%$ of the taught courses; 2) either a surveying core, or a cartography core; 3 ) a selection of options, some more suited to cartography students, some more cartographic, and 
some suitable for either specialism; 4) an MSc project. This model ran successfully for several years, generally recruiting well, with more surveyors than cartographers. Following pressure from the University for staff to opt for early retirement, a looming reduction in Geomatics staff early in this century led to the remaining staff mainly focusing on the undergraduate programme, with plans for PG teaching to cease. However, a funding opportunity arose to continue postgraduate teaching in cartography, so the MSc in Topographic Science was dropped in favour of a much more narrowly focused MSc programme in Cartography \& Geoinformation Technology launched in 2004.

Staffing shortages and internal University politics lead to the decision to stop the undergraduate programme by 2008 , much to the concern of the Scottish surveying community. Pressure from industry and some significant funding lead to the University agreeing to re-institute a 1 year master's programme in surveying, commencing in 2007. This was the MSc in Geospatial \& Mapping Science (G\&MS) and in line with its introduction there was a re-structuring of the cartography programme, to become MSc in Geoinformation Technology \& Cartography (GT\&C). The restructuring enabled some core course and options to be shared, much like the programme of the mid-1990s. Shared courses include Fundamental of Geomatics (which covers datums, projections, transformation, etc); an introduction to GIS; a course in research and professional issues; and the Topics in Geomatics course which covered much of semester 2, and allowed student to choose from several short focused study block on a wide range of topics,.

As these programmes developed, and to reflect changes in industry, while the basic structure remains similar to that of 2007, there is more overlap between the programmes in core material, with GT\&C student now joining the first surveying course as increasingly those employed in GIS are expected to able to carry out at least basic field data capture. Topics in Geomatics was replaced by more substantial courses dedicated to each programme to reflecting the need to cover some developing areas in more detail (e.g. laser scanning or web mapping). To an extent, this removal of optional topics was never optimal, but reflected the need to extend the core material covered by each programme within the limitations of 1 year delivery. Reflecting the desire to offer greater choice to students in what they study and that increasingly some students are entering with existing skills/knowledge is some core aspects, such as GIS, from 2021 there will be a new flexible programme which retains much of the core shared by the two existing programmes, but allows choice from courses across both programmes, plus some appropriate courses from other MSc programmes in the University (e.g. Environmental Statistics).

In recent years the GT\&C programme has been successful in attracting students, with numbers increasing from typically $12-15$ in the first 10 years from its introduction in 2007, to 40 in 2020-21, with applications up again for 202122 (in contrast the Surveying programme has remained stable with $\sim 25$ students). In asking students why this programme, many say it is having Cartography in the title that attracts them and differentiates Glasgow from the many programmes in GIS available. It is the only MSc programme in the UK to use the term 'Cartography' in this way and although the content of the programme significantly overlaps with many GIS programmes, the focus on understanding the underpinnings of geospatial science, such as coordinate reference systems, the association with surveying, and the emphasis on cartography does appear effective in recruitment.

Looking to the future, the appointment of new staff ( 3 permanent positions in the last 15 months) will clearly have an impact on the curriculum as they introduce their specialist knowledge. The focus of the GT\&C programme is likely to move more towards a Data Science approach, particularly focusing on handling big data, but also web delivery and topics such as indoor navigation. The importance of computer programming within the teaching of geospatial sciences has varied considerably over the years, as we see periods where industry demand this, and periods where the use of existing systems is prioritised. Despite the fantastic capabilities of some 'off-the shelf' systems compared to a few years ago, we are in a period where more employers expect at least basic programming capability from MSc graduates. We reflect this by including an introduction to Python in a core course, which is developed further in later courses, and one of the new appointments has a clear focus on developing web based programming such as javascript. This is reflected more generally across the School of Geographical \& Earth Sciences where more staff are engaged with programming and a very active, self-support group has become established, and continued to meet weekly during lockdown.

Three years ago a Work Placement option was introduced for the surveying MSc, where the 4 month MSc project is replaced by a 6 month work placement with an industrial partner. This is unique within the University and required approval at the highest level to ensure that the quality of education was retained with this novel model. Given the success of this, a similar option will be pursued for the GT\&C programme, further enhancing our strong ties with industry.

Clearly, everyone has seen major impacts of the pandemic in terms of teaching, with remote delivery becoming the norm. We had already been involved in some projects using remote delivery of short courses, and this will no-doubt increase, but our experiences of the last year seem to indicate that a blended learning model is more appropriate for what we want to achieve than a full on-line remote delivery model. Bringing students together in a classroom for discussion and mutual support still has many benefits.

Currently the future looks bright for the future of cartographic and geospatial science education by the University of Glasgow. 